\title{
Philosophical Potencies of Postphenomenology
}

\author{
Martin Ritter ${ }^{1,2}$ (D)
}

Received: 9 March 2021 / Accepted: 8 August 2021 / Published online: 27 August 2021

() The Author(s) 2021

\begin{abstract}
As a distinctive voice in the current philosophy of technology, postphenomenology elucidates various ways of how technologies "shape" both the world (or objectivity) and humans (or subjectivity) in it. Distancing itself from more speculative approaches, postphenomenology advocates the so-called empirical turn in philosophy of technology: It focuses on diverse effects of particular technologies instead of speculating on the essence of technology and its general impact. Critics of postphenomenology argue that by turning to particularities and emphasizing that technologies are always open to different uses and interpretations, postphenomenology becomes unable to realize how profoundly technology determines our being in the world. Seeking to evaluate the postphenomenological (in)ability to radically reflect on the human being conditioned by technology, I discuss the two most pertinent criticisms of postphenomenology: an "existential" one by Robert C. Scharff and an "ontological" one by Jochem Zwier, Vincent Blok, and Pieter Lemmens. Assessing the ontological alternative, I point to incapacity of Heidegger's concept of Enframing to do justice to material technologies. Simultaneously, I acknowledge the necessity of speculating on (the concept of) technology as transcending concrete technologies. Such speculating would be instrumental in reviving Ihde's idea of non-neutrality of technology in its full philosophical potency.
\end{abstract}

Keywords Ihde $\cdot$ Ontology $\cdot$ Perception $\cdot$ Postphenomenology $\cdot$ Technological mediation

\section{Introduction}

Postphenomenology is both a well-established and vigorously evolving philosophical movement, initially outlined by Don Ihde, the author of "the first full-scale philosophical analysis of technology by an American” (Durbin, 2006, 95-96). Taking
Martin Ritter
ritter@flu.cas.cz
1 Institute of Philosophy, Czech Academy of Sciences, Prague, Czechia
2 Department of Philosophy, University of Vienna, Vienna, Austria 
inspiration from the phenomenological and pragmatist traditions of philosophy, postphenomenology as a "hybrid" phenomenology fosters the development of a distinctive philosophy of technology which concentrates on how technologies mediate the world and the human beings in it. Claiming allegiance to the so-called empirical turn in philosophy of technology (see Achterhuis, 2001), postphenomenology avoids the more speculative approaches of "classical" philosophy of technology personified by such thinkers as Ellul or Heidegger. The method of postphenomenology includes empirical work "as a basis for philosophical reflection" (Rosenberger \& Verbeek, 2015, 31). More concretely, it bases its conclusions on case studies, i.e., on analyzing concrete empirical inter-relations and interactions between humans and technologies. Such an approach, or methodology, displays obvious strengths. It provides highly interesting descriptions of human-technology relations and their impact. Yet, critics of postphenomenology have repeatedly expressed doubts regarding its ability to offer a properly radical reflection on the "technological condition" of our being in the world.

In the following, I will give voice to these worries and discuss the postphenomenological (in)ability to reflect radically on the human being with technology. Reviewing one of Ihde's outlines of postphenomenology, I will focus especially on his idea of the "non-neutrality" of technology. Then, I will devote attention to what I see as the most important critical appraisals of postphenomenology: an "existential" one by Robert C. Scharff and an "ontological" one by Jochem Zwier, Vincent Blok, and Pieter Lemmens. Both criticisms demonstrate that, to put it very roughly, postphenomenology, when focusing on empirically observable human-technology relations, evades the question of the general impact of technology. Subsequently, I will inspect the alternatives suggested by critics. I will explicate why neither the Heideggerian ontological approach nor the postphenomenological empirical one suffice: neither is able to do justice to our concrete experience as conditioned by technology. Paradoxically, to elucidate our empirical experience, we need to conceptualize technology in a less empirical way than is done by postphenomenology.

The aim of my discussion is not to deny the approach of postphenomenology but rather to duly appreciate its impetus by focusing on what postphenomenology could show us when realizing its full potency regarding the influence of technology on the human being in the world. I believe that the critics rightly point to the postphenomenological inability to address a "large-scale pattern" connected with and conditioned by technology. Yet, whereas they suggest alternative approach(es), I would like to show that postphenomenology can reformulate its program, or, more precisely, change its current modus operandi to be able to realize its own program. I aim at demonstrating that postphenomenology does not have to think the "general pattern" as something large, or as Technology, but rather as something with large impact by pervading what seems small, i.e., our always individual perception. Hence, I do not argue for abandoning postphenomenology but rather for turning back to its original impetus by reconsidering its methodology. Ihde is an adventurous thinker, and one who surely would not want to be tied up by a strictly defined methodology, yet I believe that a methodological reflection might be instrumental in fulfilling the intentions of postphenomenology. 


\section{Program}

Ihde started to label his approach as postphenomenology in 1993, in Postphenomenology: Essays in the Postmodern Context (Ihde, 1993), thus expressing his indebtedness to both phenomenology and postmodern non-foundationalism (more concretely: relativism and pragmatism). Nevertheless, all these elements are already present in Technology and the Lifeworld (Ihde, 1990), where he distinguishes three programs of (postphenomenological) philosophy of technology.

"Program one: a phenomenology of technics" aims at elucidating the basic structures of experience in human-technology relations while this analysis is "centered upon the ways we are bodily engaged with technologies" (Ihde, 1990, 72). Ihde distinguishes four kinds of human-technology relations: embodied, hermeneutic, alterity, and background ones. In both the embodied and hermeneutic relations, technology mediates our experiencing of the world. When embodying a pair of glasses, or driving a car or even a bulldozer (cf. Ihde, 1990, 75), my perception changes-due to the technology, I sense the world differently. In the embodied relation, I perceive through technology, whereas in the hermeneutic relation, I do so with it, as in the case of reading a thermometer. In contrast to both the embodied and hermeneutic relations, in alterity relations technologies become quasi-others - we relate to them and can interact with them. We do not relate, strictly speaking, to a background technology: it withdraws, yet "as a present absence, it nevertheless becomes part of the experienced field of the inhabitant, a piece of the immediate environment" (Ihde, 1990, 109). An example here may be shelter technologies or even clothing (cf. Ihde, 1990, 110).

Ihde's "program two: cultural hermeneutics" goes beyond the sphere of individual human-technology relations and focuses on the relation between technology and culture. Specifically, Ihde seeks to identify "the ways in which cultures embed technologies" (Ihde, 1990, 124). Analyzing the topic of technology transfer, he underlines that technologies need (not only technological) infrastructure to function as technologies. This is because "the artifact 'is' what it is also in relation to [the] cultural field" (Ihde, 1990, 128). Underlining that the reception, or appropriation, of technologies is culturally conditioned, Ihde argues against understanding technology as either neutral or determinative. Technology is neither a neutral means we control nor a "sovereign" controlling us; it is neither a mere instrument to be used nor an autonomous substance with its own dynamic. Seeking to "reframe the question" regarding the (im)possible control of technology, Ihde points to "multistabilities" in both "human-technology relations and even more strongly in the complexities of technology-culture gestalts" (Ihde, 1990, 146). To label his own position regarding the question of the influence of technology on humans, he chooses the term "non-neutrality."

Though arguing against technological determinism, Ihde concludes his cultural hermeneutics saying that "[a]t the end of this second program, ... a different form of technological-cultural determination has reappeared" (Ihde, 1990, 161). His "third and final program," then, concentrates "upon the unique curvatures of the contemporary lifeworld" (Ihde, 1990, 161) to identify "the shapes to technological 
non-neutrality in this postmodern lifeworld" (Ihde, 1990, 162). Ihde recognizes two such "curvatures" or "vectors": pluriculturality and a decisional burden. The first one makes us, or requires us, to have a "compound eye," "a vision refracted by a plurality of views" (Ihde, 1990, 220). And, since high technologies make many things previously impossible possible, we cannot but choose-therefore, we find ourselves burdened with (too) many decisions to make.

Instead of discussing whether Ihde's description of his "contemporary lifeworld" was factually right, allow me to formulate some methodological questions. First, pointing to the multistability of technology, Ihde maintains that "the predictions of analytic uniformity (Marcuse), of the victory of technique (Ellul), and even of the sheer world of calculative thought (Heidegger) are wrong" (Ihde, 1990, 159). Yet, one can read his "program three" as describing a just as uniformly determined lifeworld, a world just as burdened and permeated with technology, although in a different way. Hence the second question: does Ihde accept, in his program three, a form of technological determinism? When interpreting Ihde, Peter-Paul Verbeek asks the very same question and reformulates it in this way: "Is the cultural relation to technologies multistable, or do technologies have a culture-changing power?" (Verbeek, 2001 , 138). Verbeek then goes on to answer this question, taking television as his example, by emphasizing that technology is unthinkable without an already cultural appropriation of it. "Once a relation to a technology is taken on, the relation to the technology is stable rather than multistable and the technology is able to influence the relation taken toward it, without its influence on the relation being deterministic. In principle, several cultural relations are always possible toward an artifact" (Verbeek, 2001, 139). In other words, technology can influence culture only after a cultural relation to it has already been taken - and this influence is not deterministic as other cultural relations always remain possible. I do not find this argument persuasive. First, we should consider empirical facticity, or at least real-life probability (of different relations to television), rather than theoretical possibility. Second, and more importantly, the possibility of multistable relations has nothing to do with the question of the "culture-changing power" of technology. This question is after, to use Verbeek's description, the influence of technology we already relate to-can such technology determine our culture? This question asks not (only) whether technology can determine our already cultural relation to itself but whether it can determine, or re-structure, our (cultural) being in the world as such.

By formulating this question, I signal the need for more clarity regarding Ihde's concept of non-neutrality. One can acknowledge technologies as always, in principle, multistable, and still ask whether there is a process by which technology, in its non-neutrality, shapes our lifeworld. Allow me, then, a provocative simplification: Whereas program three can be interpreted as a culmination of the research agenda formulated by Ihde, postphenomenology in its further development has inclined to concentrate on program one, to dispose of program two by pointing to technology-society relations as multistable, while program three has simply disappeared from the horizon. I claim that this tendency is neither necessary nor desirable. In fact, Ihde himself says that technology "constitutes a framework for contemporary choice" (Ihde, 1990, 161). Of course, one can always insist that technology is not deterministic unless it determines the choice itself. But, I argue that the impact of 
technology is just as important, and even more fundamentally, when it delimits the framework of choices: technology can be conceived of as culture-changing element exactly insofar as it frames our choices.

\section{Criticisms: Intrusion and Subversion}

Ihde connects his differentiation between programs one and two with the dual meaning of the term perception: it means both immediate bodily sensing and meaningful understanding - when things "make sense" to us. "What is usually taken as sensory perception (what is immediate and focused bodily in actual seeing, hearing, etc.), I shall call microperception. But there is also what might be called a cultural, or hermeneutic, perception, which I shall call macroperception" (Ihde, 1990, 29). According to Ihde, this duality "calls for a double-sided analysis of the range of human-technology relations within the limits of microperceptual and bodily experience; the other side of the analysis must remain that of a cultural hermeneutics that situates our existential life" (Ihde, 1990, 30). Although Ihde himself claims that the two dimensions are "intertwined" and there is "no microperception (sensory-bodily) without its location within a field of macroperception and no macroperception without its microperceptual foci" (Ihde, 1990, 29), he analyzes them separately, i.e., under the headings of "a phenomenology of technics" and "a cultural hermeneutics."

This separation has repeatedly been criticized by perhaps the most persistent critic of postphenomenology Robert C. Scharff. Here, allow me a longer quotation: If Ihde thinks that "Program Two can wait until Program One is well underway," then it "brings matters to a screeching halt at a place where Ihde obviously does not want to be-namely, stuck, without a genuinely phenomenological reply, between two competing traditional tendencies-one 'subjective,' the legacy of the philosophies of consciousness, where thought's reference to 'cultural context' is always optional, the other 'objective,' the legacy of post-Kantian critical philosophy, where the cultural conditions of thought must always be given the first word" (Scharf, 2020, 74-75). Simply, Scharff argues against separating programs one and two. Their inseparability is perhaps most visible in the case of the hermeneutic humantechnology relation where my singular representing the world with a hermeneutical tool (a case of micro-perception in Ihde's framework) is unthinkable without its cultural framework. Since micro-perception is always already macro-perceptual, and hence cultural, it seems necessary to analyze how this intertwining influences perception as such (or as a "whole"): how the macro is present in the micro, or how the micro is informed by the macro. Ihde does not offer such an analysis. He cannot unite programs one and two into a holistic approach because the two programs do not complement each other-they cannot make a whole. Scharff might seem to be exaggerating when applying the subjective-objective and/or the consciousness-culture dichotomies to Ihde's conception, yet he rightly points to the discontinuity and inconnectability of programs one and two. They cannot be interwoven because Ihde conceives of micro-perception merely as (in) an individual-technology relation, and approaches macro-perception as the problem of macro-dimension, i.e., of society-technology relations. Two such approaches surely offer important 
perspectives on technology, yet they do not account for perception of the world as neither only individual or "micro" nor only cultural or "macro," but both at once. Building on Scharff's idea, we can say that the social and the cultural cannot be understood merely "as 'another' layer or level, capable of being descriptively added to or ignored by analyses of the perceptual." Instead, we need to approach them as "dimensions of one seamless condition of being-in-the-world" (Scharff, 2006, 135; cf. Scharf, 2020, 74), and specifically of "perceiving-in-the-world" (when perceiving implies seeing possibilities for action). I will outline such an approach at the end of this paper.

Pointing to the multistability of technology, Ihde proclaims technological-cultural development as ambivalent and open, or simply open. Scharff does not approve Ihde's account of the world "in which technoscience is definitive of the dominant atmosphere" (Scharff, 2006, 139). He doubts this atmosphere as that "of expansive understanding, openness to ontological variety and difference" (Scharff, 2006, 140). In this context, he challenges Ihde's refusal of less approving approaches to technology: the "complaint about technoscientific hegemony is neither a representation of something in the heads of pessimistic human beings - a macroperceptual part of their 'culture' - nor out there in the world, as the manifestation of some inevitable causal process" (Scharff, 2006, 139). Ihde is unable, according to Scharff, to fully appreciate technology as "existentially intrusive" (Scharff, 2006, 138): technology intrudes our existence while this intrusion is reducible neither to an objective ("inevitable causal") nor to a subjective process or element (a negative point of view). "It articulates," Scharff continues, "an experiential sense of the dominant mood 'between,' and as clearing the space 'where,' we encounter things, and it differs from Ihde's own understanding of the age only in being more explicit and less joyful" (Scharff, 2006, 139).

Scharff's critical remarks I have summarized so far question how Ihde concretely realizes his program and how he undervalues the "existential" impact of technology, i.e., its impact on the framework of our existence—on the "lifeworld," to use Ihde's own term, as the "where," to speak with Scharff, we encounter things. Both these criticisms effectively aim at Ihde's method as unable to address how profoundly our being in the world is conditioned by technology. Scharff's next objection is different. It assaults Ihde's progressivist techno-optimism. Paying attention to the founder of positivism Auguste Comte, Scharff maintains that "we are all, to some extent, happy Comtean pragmatists" (Scharff, 2006, 141) —and we should reflect on this "setting" as permeated by Comte's progressivist law of three stages (the theological, the metaphysical, and the positive). "Viewed in relation to Comte's law, it appears that philosophers of technology who favor concrete studies and distrust everything else may actually be giving new life to Comte's technoscientific optimism, at the very moment when the whole cluster of background assumptions built into his understanding - assumptions about human nature, about the endless malleability of scientific and engineering practices, about the control of nature and social reorganization having basically the same ground plan-are themselves being identified as main sources of our discomfort" (Scharff, 2012, 173). This reflection cannot be simply dismissed as nostalgic or outdated. Informed by Heidegger's idea of destruction, Scharff reminds us how deeply inscribed our conceptual schemata indeed are. 
"It is tempting to assume," Scharff writes, "that nineteenth century scientism is just a 'world-view,' and that now we live in the twenty-first century where we are perfectly capable of simply 'choosing' another one. But this is self-deception. Positivism is still too close to us to be understood as an interesting idea. In his reflective utilization of the three-stage law, Comte says out loud what it still seems natural for North Americans and many Europeans to simply assume about science, technology, and society" (Scharff, 2012, 165). According to Scharff, Ihde does not see how his approach "already articulates a neo-enlightenment spirit and is thus carried silently into his project from the very beginning, providing the background understanding of "where' all his descriptions are being worked out" (Scharf, 2020, 83). This reflection offers an explanation as to why Ihde lacks, according to Scharff, "an experiential sense" of our being with technology: it is due to his inability to overcome what is still our "natural" positivist worldview.

In their "phenomenological analysis of postphenomenology," Zwier et al. (2016) draw out a similar line of reasoning, yet they more explicitly utilize Heidegger's late philosophy of technology. According to postphenomenology, we need to investigate technologies in an empirical and pragmatic way. Such an approach is supposed to bring, instead of essentialism and transcendentalism, a more adequate philosophy of technology. Underlining the emphasis on adequacy, the authors ask: "in what kind of experiential correlation is the postphenomenological researcher taken up when relying on content-pragmatism to provide an adequate depiction of the phenomenon" (Zwier et al., 2016, 321)? When developing an adequate theory of the human-technology relations, namely "mediation theory," the postphenomenological method "overlooks the element in which it is itself absorbed when confronting human-technology relations," i.e., the "theoretical attitude" (Zwier et al., 2016, 324). According to Zwier, Blok, and Lemmens, "this theoretical mediation is itself pragmatic insofar as it grounded in utility and effect, and can therefore be understood as technical mediation" (Zwier et al., 2016, 326). Of course, this step from exposing the pragmatic character of postphenomenology to claiming that its theoretical attitude is technologically mediated is by no means self-evident. An attitude can be pragmatic, or even utilitarian, without being technological, or technical. Obviously, the authors define the technical in a very specific, and non-intuitive, way-what they have in mind is Heidegger's concept of technology. Their subversive reading of postphenomenology not only defends Heidegger against misinterpretation but uses his ideas to weigh up the postphenomenological attitude itself. "The central point is that Heidegger's understanding of the essence of modern technology - Enframing - concerns what we have discussed in terms of the phenomenological concept of technical mediation, and can therefore neither be reduced to essentialism (Ihde) nor transcendentalism (Verbeek)" (Zwier et al., 2016, 328). The authors thus call for rehabilitating Heidegger: the concept of Enframing must not be read as, and reduced to, a value judgment disparaging modern technology; we need to rehabilitate it in its ontological potency. Yet, the authors are, in the last instance, quite conciliatory regarding the approach of postphenomenology: they demand neither its being abandoned nor radically reconceptualized. Instead, they appreciate postphenomenology for its ability to elucidate "the consequences of specific technologies and their respective mediations," and even accept the critique of Heidegger, "to the extent that 
it concerns the theoretical analysis of human-technology relations" (Zwier et al., 2016, 327). Simply put: although postphenomenology is unable to address the ontological dimension, there is no problem with it.

Remarkably, even some postphenomenologists acknowledge, rather accidentally, the merits of Heidegger's non-empirical approach. The editors of Postphenomenological Methodologies write: "The problem with this [i.e. Heideggerian] approach is not that it is wrong per se-indeed, as an interpretation of a large-scale pattern, it might be alarmingly accurate - but that the things themselves cease to matter" (Aagaard et al., 2018, xvi). All the critics point exactly to the "large-scale pattern" as generally characterizing "where" we live with technology (Scharff) or even the way postphenomenology approaches our destination (Zwier, Blok, and Lemmens). In this context, we can fully appreciate Scharff's discontent with the programs' one/ two separation: it is part of a more general criticism of postphenomenologists' preferring to focus, positively, on particular empirically inspectable human-technology relations while rather evading question(s) concerning the influence of a more generally conceived technology and denying, negatively, its impact as deterministic. Is ignoring the general pattern justifiable?

\section{Alternatives}

According to Robert Rosenberger, postphenomenology intends to "shed light on the multiple ways that users and the world are 'shaped' in particular cases, neither by identifying their essences, nor by accessing some deeper epistemic foundation, but by critically contrasting various real and possible coshapings" (Rosenberger, 2017, 489-490). Rosenberger insists on the multistability of technology and underlines, similarly to Goeminne (2013), a "postmodern political character" of postphenomenology (Rosenberger, 2017, 489). He connects postmodernity with a nonfoundational and non-essentializing approach and differentiates it from one looking for essences and foundations. In contrast to Zwier, Blok, and Lemmens, who call for reviving Heidegger's concept of the essence of modern technology, Rosenberger speaks about "the metaphysical baggage of Heidegger's foundational account" (Rosenberger, 2017, 486). Nevertheless, Rosenberger is aware of the challenge thrown down by the critics of postphenomenology and encapsulates it thus: postphenomenologists are called upon to "show that there is not a pernicious pattern in our contemporary relationship to technology in general. That is, if postphenomenologists are making the hard claim that our relationships to technologies are actually always ambivalent and subject to change, then this requires substantiation just as do more foundational or essentializing accounts" (Rosenberger, 2017, 492). I hold in high regard Rosenberger's effort to meet this challenge by outlining a precise postphenomenological methodology. Nevertheless, I do not think that his argumentation quite reaches its goal. As already indicated regarding Verbeek's interpretation of Ihde's program three, the challenge cannot be reduced to asking whether there is a "pattern in our contemporary relationship to technology in general": the question is not about our relating to technology but about the influence of (our being with) technology on our being in the world as such (our relating to technology included). This 
question is irreducible to deciding whether our relating to technology is diverse or uniform; it asks whether technology has a general impact, i.e. determines a "general pattern" of our being in the world.

I will formulate this question more concretely in what follows. At this juncture, let me just comment on how Rosenberger contrasts postphenomenological postmodernism with (phenomenological) foundationalism. I insist that both postphenomenological and phenomenological "investigations are always posed from situated, embodied, and concrete contexts" (Rosenberger, 2017, 488). Yet, not only can we make "structural claims" (about technology) based on situated and contextualized cognition, as Rosenberger seeks to demonstrate, but this very situation may have general features, or even form a general condition of our embodied reflections. This is what the critics of postphenomenology point to: the determination to prefer, or even seek out, multistabilities of technologies despite the experience of the "largescale pattern" can be interpreted as generally conditioned by a neo-enlightenment "spirit" (Scharff) or Enframing (Zwier, Blok, and Lemmens). The emphasis on particularities might not be so innocent and harmless as proclaimed by postphenomenologists. This is what Scharff maintains when suggesting, against the pragmatically postmodern approach, "reading through his [i.e. Ihde's] enlightenment impediments and responding experientially, currently, 'from here,' to what his actual accounts disclose to $u s$... without buying into his enlightenment suspicion that all generalization-especially if it displays overt socio-political concern-is necessarily essentialist" (Scharf, 2020, 84). I would like to underline that the approach suggested by Scharff does not imply one's becoming essentialist or foundationalist: one just seeks to do justice to one's own particular situation in its general characteristics.

Zwier, Blok, and Lemmens explicitly demand a return to Heidegger's late ontology. "Heidegger's notion of Enframing ... must be rehabilitated as highly relevant for an ontological questioning of technology" (Zwier et al., 2016, 328). Whereas Scharff exposes postphenomenology as conditioned by a positivist worldview, the authors rehabilitating Heidegger understand the approach of postphenomenology not only as historically situated but as "technically mediated" in an ontological sense, i.e., as "enframed." I have already indicated that the connection between the concept of Enframing and an intuitive or "natural" meaning of technology is disputable-I will return to this problem in the next section. Yet, there is another problem with the call for an ontological turn. The authors remain rather vague in defining their approach and how to go about realizing it: the research agenda they outline is indefinite and (too) broad. First, the authors intend to explore whether each technical making and willing is necessarily anchored in Enframing as the mode of revealing, thus casting doubt on the universality of the concept of Enframing. Second, they would like to connect Heidegger's conception with “our present ecological situation ... as a fundamental "how' of how things appear to us" (Zwier et al., 2016, 331). Though I fully agree that we need to (re)think the relation between ecology and technology, I continue to find it difficult to connect Heidegger's concept of Enframing with our "ecological situation" and to give sense, in the Heideggerian framework, to the question of whether the appearing of the world "involves a mutation in due to the earth appearing as unworldly" (Zwier et al., 2016, 331). Allow me to mention that, in Heidegger, the earth cannot be but "unworldly," as it stands against the world, or, if you 
wish, in its background. Let me be clear: I do not wish to quarrel over the interpretation of Heidegger. My point is that I cannot see how to connect his late ontology with our present ecological situation to better understand it. Third, the authors not only question the so-called empirical turn as realized by postphenomenology but also criticize Heidegger's inability to consider how concrete technological artifacts " "mediate' on an ontological level," i.e., condition "how being reveals itself" (Zwier et al., 2016, 330). Postphenomenology obviously cannot raise this question due to focusing merely on "ontic human-technology relations." Yet, even Heidegger cannot address it because, "for him, concrete artifacts are only encountered by way of the revealing of modern technology" (Zwier et al., 2016, 330). Can particular technologies have ontological impact? Peering out over all these open questions, I do not get a clear idea of how the revival of Heidegger should be realized. Moreover, since the authors formulate or imply quite a few objections or qualifications regarding Heidegger's approach, they rather bedim than clarify the meaning of the "ontological dimension" (or "moment" or "level" or "terms") emphasized by them.

\section{Philosophy of Technology}

I cannot here properly go into how the authors of the phenomenological analysis of postphenomenology further develop and utilize their ontological philosophy of technology based on Heidegger's ideas (see, e.g., Zwier \& Blok, 2017, 2019; Blok, 2019). That said, allow me to turn the attention to the subversive core of their interpretation of postphenomenology, namely the concept of Enframing, which they see as ontologically mediating postphenomenology. I do agree with their rejecting the manner in which postphenomenology usually interprets Enframing. Ihde misses the point when claiming that "the elevation to technology with a capital ' $\mathrm{T}$ ' emasculates Heidegger's philosophy of technology from making any nuanced conclusions about particular technologies (without capitals) because everything stands under the revealing power of enframed standing-reserve" (Ihde, 2010, 109). Here he misses the point, as Heidegger is neither interested in particular technologies nor seeks to capture the essence of technology by identifying their common "nature." Nevertheless, Ihde rightly draws attention to Heidegger's lack of interest in material technologies. Instead of analyzing them as conditioning our being in the world, Heidegger sees and approaches the problem the other way around: we see all things, and not only particular technologies, in a technological way because of Enframing. As Zwier, Blok, and Lemmens put it, according to Heidegger, "concrete artifacts are only encountered by way of the revealing of modern technology" (Zwier et al., 2016, 330). Heidegger understands Enframing as an event in the history of Being, an event inexplicable by technologies but rather elucidating them, and even making them possible. Such an approach has both its pros and cons. More specifically, one can acknowledge Heidegger's concept of Enframing as capturing the "large-scale pattern" of our being in the world and yet maintain that, since it does not appreciate concrete technologies, it does not offer a philosophy of technology.

Postphenomenology, by contrast, is lacking in, or insufficient as, philosophy of technology. Schematically speaking, whereas Heidegger's concept seems able to 
capture the "pattern" but does not elucidate it as conditioned by technology (since it loses touch with particular technologies), postphenomenology stays in touch with technologies but is unable, or at least unwilling, to address the "pattern" conditioned by them. Postphenomenology is unwilling to acknowledge this pattern even though Ihde's reflection on the "curvatures" or "vectors" of the contemporary "lifeworld" (Ihde, 1990, 162) may very well lend itself being interpreted as pointing to exactly just that. Indeed, instead of looking for the general impact of technology, postphenomenology suggests forsaking the very category of technology. Rosenberger maintains that the "category of 'technology' could be added to Haraway's list of local abstractions that should never be mistaken for preexisting essences, nor ever mistaken for providing a preexisting foundation. Verbeek's postphenomenological conviction that subjects and the world are things that are co-shaped though technological mediation is resonant with Haraway's insights on this point" (Rosenberger, 2017, 489, n. 18). But, pace Rosenberger, such a conceptualization of technology, i.e., one that refuse to "substantiate" technology, makes the very concept of technological mediation senseless. We need to somehow define technology to be able to meaningfully speak of technology as that through which subjects and objects are mediated. If postphenomenology wants to maintain the concept of technological mediation, it needs to define the category of technology and it needs to do it for quite a practical reason: to be able to realize that technological mediation is taking place somewhere. (Besides, a concept of technology might justify the focus on this or that technology: Is postphenomenology justified in focusing mostly on the newest technologies, and not, for example, on the arguably still influential industrial ones?) Remarkably, we come here, from a different direction, to a similar conclusion as in Heidegger's case. An attempt to utilize Heidegger's concept of Enframing necessarily faces the problem of its being detached from technologies: based on Heidegger, one can claim that postphenomenology is mediated by Enframing, yet one cannot really claim that this mediation is technological. Similarly, postphenomenology can surely claim that something is mediated, yet if it wants to claim it as technologically mediated, it cannot get rid of the concept of technology and cannot avoid the task of defining it.

Casting doubt upon the so-called empirical turn promoted by postphenomenology, Zwier, Blok, and Lemmens ask "whether focusing on concrete technological things is sufficiently empirical ... in the phenomenological sense" (Zwier et al., 330). I suggest a reformulation: Is the focus on empirically given technologies sufficiently concrete? More precisely: Does it do justice to our concrete experience? Neither the ontological approach inspired by Heidegger nor that of postphenomenology seems fit enough to accomplish the task; the former is lacking, while the latter overextending, in empirical particularities. I see the deficiency of Heidegger's approach neither in essentialism nor in transcendentalism but rather in its immaterialism, i.e., in its ignoring technological materialities and intentionalities. Heidegger conceives of technology not as something but rather as a way of approaching everything, or "how things appear to us" (Zwier et al., 2016, 331), without explicating how this ("technological") way of appearing is related to, or conditioned by, (technological) materialities. Postphenomenology, on the other side, is found too confident in assuming that technology is simply "at hand" identical to technological artifacts. One can certainly examine any artifact (in its mediating power), yet if we want to 
examine technological mediation, we need more: We need to be able to identify the technicity of a thing (for a more elaborate discussion of this problem, see Ritter, 2021) and even to see technology as irreducible to particular things, or particularities. How to go about doing this? Must we define in advance (or a priori) the essence of technology to be able to identify the things/processes in the world that are technological? Such an approach would surely be in danger "that the things themselves cease to matter" (Aagaard et al., 2018, xvi). But we are not in an either-or situation here, i.e., we do not have to choose either technology or technologies. We need both. Or, practically, we need to both take into account particularities "naturally" seen as technological and speculate, philosophically, about the (variable) "category" of technology and its impact on our being in the world.

\section{Revising the Program}

What is at stake in both Ihde's program three and in the existential and ontological critiques can be called ontological: it is the "nature" of the contemporary world we live in, i.e., of our lifeworld. Yet we need to define the term ontology more precisely. Without discussing its meaning(s) in Heidegger's thought, let me state that in a phenomenological approach, the questions concerning being are necessarily connected or coupled with those concerning experience. To put it in a very simplified manner: analyzing being in the world necessarily means, in phenomenology, analyzing experiencing in the world. Now, the ontological dimension, in contrast to the ontical, relates not to entities we experience but rather to how we get in touch with them, or how they appear to us. In the context of postphenomenology, then, I suggest defining the meaning of the ontological, and more specifically of the ontological impact of technology, thus: it refers to the process (of) shaping the how, or the general structure, of perception. Let me recall here that, according to Scharff, the impact of technology on our existence is neither objective nor subjective. It can be called ontological, which means more concretely: technology structures our perceiving the world. Accordingly, a (post)phenomenological philosophy of technology should aim at clarifying this impact, which means that it needs to focus on technology as that which structurally shapes our experience.

The postphenomenological philosophy of technology is phenomenological exactly due to its focusing on experience. Analyzing experience, phenomenology emphasizes the role of intentionality as a "process" through which, to put it as generally as possible, an experiencer gets into, or find themselves in, a relationship with an experienced world. I deliberately make use of this ambiguous formulation to underline that intentionality does not have to be thought of as based in, or constituted by, the subject. Accordingly, phenomenologists after Husserl have repeatedly criticized his subjectivism and outlined various ways of overcoming it - to do justice to experience itself. Unfortunately, Ihde has not shown much interest in the evolution of contemporary phenomenology (after Merleau-Ponty), and postphenomenology has gradually diverged from phenomenology. With its inter-relational ontology, postphenomenology now pays attention to relations rather than intentionality. More concretely, though acknowledging that both subject and object arise only through/ 
after (technological) mediation, postphenomenologists analyze how humans relate to technologies and how these technologies influence, when being used, experiencing humans/subjectivities and the experienced world/objectivities. The advantage of this method lies in its working with empirically given entities: humans and technologies. As already explained, postphenomenology is then able "to shed light on the multiple ways that users and the world are 'shaped' in particular cases ... by critically contrasting various real and possible coshapings" (Rosenberger, 2017, 489-490). However, such an approach is unable to do something else: to think technology not only as an object we interact with but also as "something," to use a spatial metaphor, which stays in, or steps into, the background and influences intentionality as neither subjective nor objective. Such a functioning of technology may remind us of Ihde's background human-technology relation. Yet, whereas Ihde conceives of the technology in the background as a "part of the experienced field of the inhabitant, a piece of the immediate environment" (Ihde, 1990, 109), technology as "backgrounding" intentionality is neither part nor piece of what we experience. Technology is not experienced here but rather conditions experiencing itself.

In my interpretation, Ihde's program three effectively claims that technology conditions us in an ontological way: it shapes the temporarily "universal" (for lack of a better word) way of our perceiving the world. Yet, Ihde does not explicate how his claims regarding the general curvatures of the lifeworld are based. To be able to do so, he would need a concept of technology irreducible to particular artifacts. Now, speculating about non-particular technology as a force being active in an ontologically united way is foreclosed in postphenomenology by its emphasis on, or rather the axiom of, the multistability of technology: in principle, technology can always be used otherwise. But this "axiom" points just and only to a theoretical—one can even say: a priori-possibility (especially in relation to particular technologies). And this possibility is unimportant when compared to the undeniably real effects of technology. Postphenomenology should not focus on possibilities (more specifically on various possible uses of particular technologies) but on the real change in the structure of our perception as conditioned not by this or that particular technology but by technology unidentifiable with empirically given technologies. This is why we need to speculate on technology and what we should aim at when doing so: we must make visible, phenomenologically, what normally remains invisible but conditions our normal vision.

Such an approach is impossible in the framework of the postphenomenological relational ontology. In fact, Ihde made it impossible already by methodologically separating programs one and two. By connecting the first program with micro- and the second with macro-perception, he makes the impression of two different kinds of perception corresponding to "humans and humans-in-culture" (Ihde, 1990, 144). But, as Ihde himself is aware of, there are no humans without, or outside, culture. When he writes that "[v]irtually all human activities implicate material culture, and this in turn forms the context for our larger perceptions" (Ihde, 1990, 18), he both reveals and simultaneously veils, by using the term "larger perceptions," the problem to be addressed. One surely can have a "large experience," but experiencing is always both "small," i.e., bodily mine, and "large," i.e., framed by its "culture." Accordingly, there are no "larger," i.e., cultural, perceptions as distinct from "small," 
i.e., non-cultural individual ones. By separating the two programs, Ihde prevents formulating what I see as the proper task of postphenomenology: that of identifying and describing technology as ontologically determining the structure of perception. To formulate it as sharply as possible: there can be no program three but one which re-connects, or interweaves, the phenomena addressed separately by programs one and two. In concord with Merleau-Ponty's proclamation, quoted by Ihde $(1993,76)$ and discussed by Scharff (2020, 71-72), that "there is an informing of perception by culture" (Merleau-Ponty, 1968, 212), postphenomenology should focus on showing the influence of technology, conceived of-speculatively-as a background culture, not merely on but rather in bodily perception.

Technology does not change just and only what we perceive (objectivity) and who we are (subjectivity), but, also, and more fundamentally, the way, or the how, we are-perceptively - in the world. What I have in mind here seems close to what Ihde mentions as "changes of sensibility" (Ihde, 1990, 167). As a phenomenological philosophy of technology, postphenomenology should focus on making technology visible exactly in its transforming sensibility, or even sense-ability. Let me be clear: I am not making the claim that technology changes culture, or "social practices and cultural frameworks" (cf. Verbeek, 2020, 152), and subsequently culture changes individual sensitivity. Rather, I am suggesting that we need to think technology itself in analogy to, or even as, culture. It remains a task for another paper to describe such an approach in more detail.

\section{Conclusion}

Must we resuscitate program three to realize the philosophical potency of postphenomenology? Not really. In fact, this potency lies elsewhere, in the intertwining of that which is addressed separately by programs one and two. In my interpretation and appropriation, postphenomenology as a phenomenological philosophy of technology cannot be divided into three separable programs but has only one: to show how perception as a place of a seemingly immediate appearing of the world is mediated by technology. Program three addressed this mediation by identifying the effects, or I would prefer to say activity, of technological non-neutrality, but postphenomenology needs to accomplish this task in a new way. Admittedly, instead of developing a concrete methodology, the present paper rather indicates what needs to be (re)thought. I have limited myself to outlining the main threads, and to specifying where current postphenomenology should be adjusted, not only because it would require another paper (if not a book) to discuss any desired methodology in more detail but also, and even more importantly, because different tools might be up to the task. Anyway, I hope to have made it clear that postphenomenology may live up to its promise when doing justice to the existential impact of technology by remaining close to perception and to human beings whose experience is never only individual but always already trans-individually mediated.

Ihde speaks of the "vectors" or "curvatures" of the lifeworld, which might suggest the world understood as an objective structure. But he obviously refers to how our "subjective" approaching the world, or simply perceiving, becomes shaped. 
Symptomatically, one can hardly decide whether perceiving itself is subjective or objective. It is both. And precisely for this reason it is so important and powerful: it does not bring out a subjective view on the objective world but presents itself as, or simply is, the place of immediate contact with the world. One surely might remark, regarding the "vectors" Ihde identifies, that they are rather obvious. Indeed, we most probably need to reveal other ones less trivial. Simultaneously, however, I would insist that the "triviality" of that which postphenomenology can show us does not make the power of non-neutral technology less powerful. As indicated above, the crucial task of (post)phenomenology consists in showing us that which is so obvious that we are unaware of it. More radically: it should show us what conditions our perception and make us see the way we see.

Acknowledgements I would like to thank Jakub Votroubek for his insightful comments on the first draft of the paper and the anonymous reviewers for their constructive criticism of the submitted version.

Open Access This article is licensed under a Creative Commons Attribution 4.0 International License, which permits use, sharing, adaptation, distribution and reproduction in any medium or format, as long as you give appropriate credit to the original author(s) and the source, provide a link to the Creative Commons licence, and indicate if changes were made. The images or other third party material in this article are included in the article's Creative Commons licence, unless indicated otherwise in a credit line to the material. If material is not included in the article's Creative Commons licence and your intended use is not permitted by statutory regulation or exceeds the permitted use, you will need to obtain permission directly from the copyright holder. To view a copy of this licence, visit http://creativecommons.org/licen ses/by/4.0/.

\section{References}

Aagaard \& Berg Friis \& Sorensen \& Tafdrup \& Hasse (Eds.). (2018). Postphenomenological methodologies: New ways in mediating techno-human relations. Lexington Books.

Achterhuis, H. (Ed.). (2001). American philosophy of technology: The empirical turn (trans: Crease, R.P.). Indiana University Press.

Blok, V. (2019). Heidegger's concept of philosophical method: Innovating philosophy in the age of global warming. Routledge.

Durbin, P. T. (2006). Philosophy of technology: In search of discourse synthesis. Technè: Research in Philosophy and Technology, 10(2).

Goeminne, G. (2013). Who is afraid of the political? A response to Robert Scharff and Michel Puech. Foundations of Science, 18, 355-360.

Ihde, D. (1990). Technology and the lifeworld: From garden to earth. Indiana University Press.

Ihde, D. (1993). Postphenomenology: Essays in the postmodern context. Northwestern University Press.

Ihde, D. (2010). Heidegger's technologies. Fordham University Press.

Merleau-Ponty, M. (1968). The visible and the invisible: Followed by working notes (Alfonso Lingus, Trans.). Northwestern University Press.

Ritter, M. (2021). Postphenomenological method and technological things themselves. Human Studies. https://doi.org/10.1007/s10746-021-09603-5

Rosenberger, R. (2017). Notes on a nonfoundational phenomenology of technology. Foundation of Science, 22, 471-494.

Rosenberger, R., \& Verbeek, P. P. (Eds.). (2015). Postphenomenological investigations: Essays on human-technology relations. Lexington Books.

Scharff, R. C. (2006). Ihde's albatross: Sticking to a 'phenomenology' of technoscientific experience. In E. Selinger (Ed.), Postphenomenology: A critical companion to Ihde (pp. 131-144). SUNY Press. 
Scharff, R. C. (2012). Empirical technoscience studies in a Comtean world: Too much concreteness? Philosophy and Technology, 25, 153-177.

Scharf, R. C. (2020). Postphenomenology, a technology with a shelf-life? Ihde's move from Husserl toward Dewey. In G. Miller, A. Shew (eds.), Reimagining philosophy and technology, reinventing Ihde (pp. 63-86), Springer.

Verbeek, P.-P. (2001). Don Ihde: The technological lifeworld. In Achterhuis, Hans (Ed.). (2001). American philosophy of technology: The empirical turn (pp. 119-146). Indiana University Press.

Verbeek, P.-P. (2020). Politicizing postphenomenology. In G. Miller, A. Shew (eds.), Reimagining philosophy and technology. Reinventing Ihde (pp. 141-155), Springer.

Zwier, J., Blok, V., \& Lemmens, P. (2016). Phenomenology and the empirical turn: A phenomenological analysis of postphenomenology. Philosophy and Technology, 29, 313-333.

Zwier, J., \& Blok, V. (2017). Saving earth: Encountering Heidegger's philosophy of technology in the anthropocene. Techné: Research in Philosophy and Technology, 21(2-3), 222-242.

Zwier, J., \& Blok, V. (2019). Seeing through the fumes: Technology and asymmetry in the anthropocene. Human Studies, 42, 621-646.

Publisher's Note Springer Nature remains neutral with regard to jurisdictional claims in published maps and institutional affiliations. 